GSA Data Repository 2017100

\title{
The overlooked human influence in historic and prehistoric floods in the European Alps
}

\author{
Elodie Brisset ${ }^{1,2^{*}}$, Frédéric Guiter ${ }^{2}$, Cécile Miramont ${ }^{2}$, Tiané Troussier ${ }^{2}$, Pierre \\ Sabatier $^{3}$, Yoann Poher ${ }^{2}$, Rosine Cartier ${ }^{1,2}$, Fabien Arnaud ${ }^{3}$, Emmanuel Malet ${ }^{3}$, and \\ Edward J. Anthony ${ }^{1,4}$ \\ ${ }^{1}$ Centre Européen de Recherche et d'Enseignement des Géosciences de l'Environnement (CEREGE),Aix \\ Marseille Univ, CNRS, IRD, Coll France, 13545 Aix-en-Provence, France \\ ${ }^{2}$ Institut Méditerranéen de la Biodiversité et d'Ecologie Marine et Continentale (IMBE), Aix Marseille Univ, \\ Univ Avignon, CNRS, IRD, 13545 Aix-en-Provence, France \\ ${ }^{3}$ Environnements, Dynamiques et Territoires de la Montagne (EDYTEM), Univ Savoie Mont-Blanc, CNRS, \\ 73000 Chambéry, France \\ ${ }^{4}$ Institut Universitaire de France, 75231 Paris Cedex 05, France \\ *E-mail: elodie.brisset@gmail.com
}

\section{Contents}

Appendix DR1: Study site

Appendix DR2: Study site map

Appendix DR3: Material and analytical procedures

Appendix DR4: Flood layers identification

Appendix DR5: Simplified pollen diagram

Appendix DR6: Age-depth model and dry bulk density

Appendix DR7: Chronological controls

Appendix DR8: Results of Mann-Whitney tests

Appendix DR9: Postcards and photographs 


\section{Appendix DR1: Study site}

Lake Allos is located in the southern part of the Europeans Alps, in the Mercantour National Park (Appendix DR2-A), France. The lake lies in a glacio-karstic depression shaped in an inherited glacier-cirque dominated by mountain peaks rising to $2670 \mathrm{~m}$ a.s.l. The lake basin consists of two distinct sub-basins: a shallow platform (20 m deep) to the north and a deep basin (42 $\mathrm{m}$ deep) to the south (Appendix DR2-B). Two tributaries with intermittent flow source the lake in clastic sediments: the Laus torrent which drains steep slopes $\left(35^{\circ}\right)$ and has built a steep fan feeding the shallow sub-basin, and the Source stream which drains an area of fractured limestones and easily erodible marls, and which enters the lake through a delta feeding the deep sub-basin in which core ALO11 was sampled (Appendix DR2-C). The lake catchment ( $54 \mathrm{ha}$ ) extends over two major geological units divided by a main fault (Jorda, 1976): the northern part of the catchment is characterized by a thrust sheet of erodible calcareous marls and carbonate conglomerates; the southern part is dominated by autochthonous sandstones eroded in decimetre-sized cryoclastic rocks, and, thus, does not contribute significantly to the lake's detrital input. Lithological contrasts determine the lake basement morphology. The catchment is currently covered by alpine meadow vegetation $(30 \%)$ and bedrock and scree $(70 \%)$. Larch trees grow on the inherited glacial step in the north. As the catchment is covered by snow and the lake frozen in winter, detrital inputs occur mainly in June and November. Summer events are generally related to local-scale convective processes and autumn events to meso-scale convective systems (Keiffer-Weisse and Bois, 2001). These autumn events, which affect extensive areas, can trigger catastrophic floods (Berne et al., 2009).

Jorda, M., La région du Lac d'Allos (Alpes de haute Provence), Carte géomorphologique Allos n 3 1/20.000. Méditerranée 3, 49-62 (1976).

Keiffer-Weisse A., Bois P., 2001, Estimation de paramètres statistiques des précipitations extrêmes dans les Alpes françaises. La Houille Blanche 1, 62-70.

Berne, A., et al., 2009, Variability of the spatial structure of intense Mediterranean precipitation. Adv. Water Resour. 32(7), 1031-1042. 


\section{Appendix DR2: Study site map}

(A) Location map of Lake Allos in the southern European Alps. (B) Bathymetric map of Lake Allos. Contours are drawn with reference to the mean water level between August and September 1961 (BRGM). (C) Aerial photography of the catchment of the Source stream, which feeds the southern deep basin of Lake Allos (IGN), and simplified lithological and geomorphological characteristics.
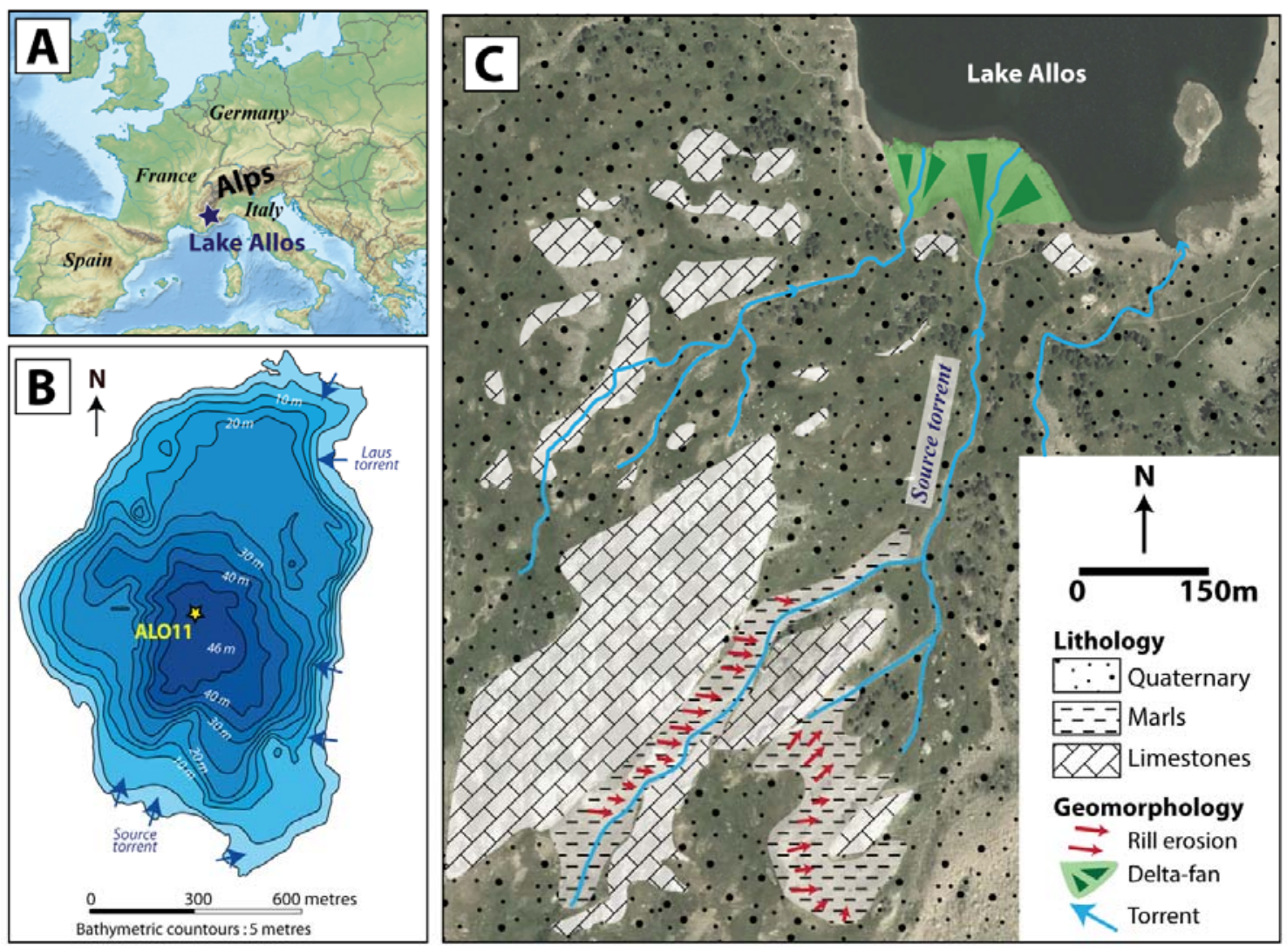


\section{Appendix DR3: Material and analytical procedures}

Core ALO11 (14 metres long) was retrieved in July 2011 in the deepest part of the lake

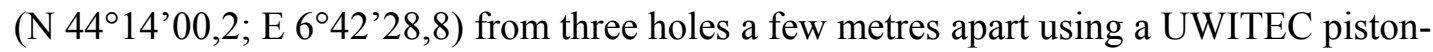
coring device mounted on a floating platform (EDYTEM). Overlapping core segments of 2 and 3 metres allowed the establishment of a continuous composite profile via visual core correlation. Microfacies analysis of flood layers was carried out on 75 overlapping thin sections of $100 \times 20 \mathrm{~mm}$. Due to sediment (notably thickness) deformation below a depth of $700 \mathrm{~cm}$ resulting from the piston coring, we focused this study on the depth interval 0$700 \mathrm{~cm}$.

Thin sections were made by MK Factory from blocks of wet sediment sampled using a Uchannel and prepared by freeze-drying and impregnation in epoxy resin under vacuum conditions (Brauer and Casanova, 2001). Thin sections were scanned at a resolution of 2300 dpi and imported into Abode Illustrator CC in order to delineate facies identified under a binocular at 40x magnification. Lamina-counting was carried out twice by two independent operators at the IMBE. Scanned images with delineated facies were merged on entire core photography to compensate for deformation effects due to block preparation. Layer thicknesses were measured using Peakcounter 2.1.5 (Marshall et al., 2012). Binocular counting allowed identifying flood layers up to a minimal thickness of $200 \mu \mathrm{m}$. The flood layers were coded according to the diameter of the coarsest particle of the layer. Three grainsize classes were defined: fine silts from 0 to $20 \mu \mathrm{m}$ (FL-1), medium silts from 20 to $50 \mu \mathrm{m}$ (FL-2) and fine sands from 50 to $100 \mu \mathrm{m}$ (FL-3) (Appendix DR4). The observed maximal particle size is $100 \mu \mathrm{m}$.

For palynological analyses, $4 \mathrm{~mL}$ of wet sediment were chemically treated following standard protocol (Faegri and Iversen, 1989) at the IMBE. The residues were sieved over 10 and $160 \mu \mathrm{m}$ meshes, mixed in glycerol and mounted on slides. A minimum of 300 pollen grains per sample were counted based on grain recognition using reference photographs (Reille, 1999). All percentage values are shown based on the total of pollen grains (Appendix DR5). The anthropic pollen curve represents fluctuations of percentage summing of Plantago, Rumex, Urtica, Mentha and Chenopodiaceae.

The chronology of core ALO11 between 0 and $700 \mathrm{~cm}$ was based on 16 accepted AMS ${ }^{14} \mathrm{C}$ dates (Appendix DR6 and DR7) obtained from terrestrial macro-remains measured by the Poznan Radiocarbon Laboratory, and ${ }^{210} \mathrm{~Pb}$ data constrained by ${ }^{137} \mathrm{Cs}$ peaks both measured using well-type, germanium detectors at the LSM on the uppermost $25 \mathrm{~cm}$ of the sediment 
core ALO-09-P2. The ${ }^{14} \mathrm{C}$ ages B.P. were calibrated using the IntCal13 calibration curve (Reimer et al., 2013). An age-depth model was computed using a monotonic smooth spline generated using the R-code package Clam (Blaauw, 2010). Taking into account temporal deposition differences between continuous and instantaneous sediment layers, the model was run on the sediment sequence after removing flood layers thicker than $200 \mu \mathrm{m}$.

Identification of regime shifts in the time series of flood frequency was carried out using the Regime Shift Detection developed for Excel (Rodionov, 2004). This method detects a regime shift when a statistically significant difference, set at 0.01 , occurs between the mean value of the variable before and after a certain point based on the t-test. Mann-Whitney tests were used to determine whether distributions of FL thickness and medians for each grain-size class (i.e. FL-1, FL-2, FL-3) vary significantly in the main vegetation cover of the lake catchment (significant level set at 0.01).

Blaauw, M., 2010, Methods and code for "classical" age-modelling of radiocarbon sequences: Quat. Geochron., v. 5, p. 512-518.

Brauer, A., Casanova, J., 2001, Chronology and depositional processes of the laminated sediment record from Lac d'Annecy, French Alps. J. Paleolimnol.: v. 25, p. 163-177.

Brisset, E., et al., 2014, A new contribution to the chronology of the deglaciation in the Upper Verdon Valley (Lake Allos, Southern French Alps): Quaternaire, v. 25(2), p. 147-156.

Etienne, D., et al., 2013, Influence of sample location and livestock numbers on Sporormiella concentrations and accumulation rates in surface sediments of Lake Allos, French Alps: J. Paleolimnol., v. 49, p. 117-127.

Faegri K., Iversen J., 1989, Textbook of Pollen Analysis. $4^{\text {th }}$ ed. Wiley \& Sons, New York, 328 p. Marshall, M., et al., 2012, A novel approach to varve counting using $\mu$ XRF and X-radiography in combination with thin-section microscopy, applied to the Late Glacial chronology from Lake Suigetsu, Japan: Quat. Geochron, v. 13, p. 70-80.

Reille, M., 1999, Pollen et spores d'Europe et d'Afrique du nord. Laboratoire de botanique historique et palynologie. $535 \mathrm{p}$.

Reimer, P. J., et al., 2013, IntCal13 and Marine13 radiocarbon age calibration curves 0-50,000 years cal BP.

Rodionov, S., 2004, A sequential algorithm for testing climate regime shifts: Geophys. Res. Lett., v. 31(9), $4 \mathrm{p}$.

Wilhelm, B., et al., 2015, Is a regional flood signal reproducible from lake sediments? Sedimentology, v. 62 , p. $1103-1117$. 


\section{Appendix DR4: Flood layers identification}

Digital image of thin sections observed under an optical microscope, and identification of flood layers according to the coarsest grain-size diameter of the layer. The sediment core consists of an alternation of organic-rich layers (OL) and flood layers (FL). Three classes have been defined: (A) Fine silts from 0 to $20 \mu \mathrm{m}$ (FL-1). (B) Medium silts from 20 to $50 \mu \mathrm{m}$ (FL-2). (C) Fine sands from 50 to $100 \mu \mathrm{m}$ (FL-3). Traces of microscale erosion at the base of FL-2 and FL-3 are visible, affecting the top of the previously deposited layer for a thickness $<100 \mu \mathrm{m}$ (i.e. flood and organic layer). Also, organic layers, composed of a mixture of algae, plant microremains, and amorphous particles, are usually intercalated between FL. These observations suggest that most of the flood layers are recorded.
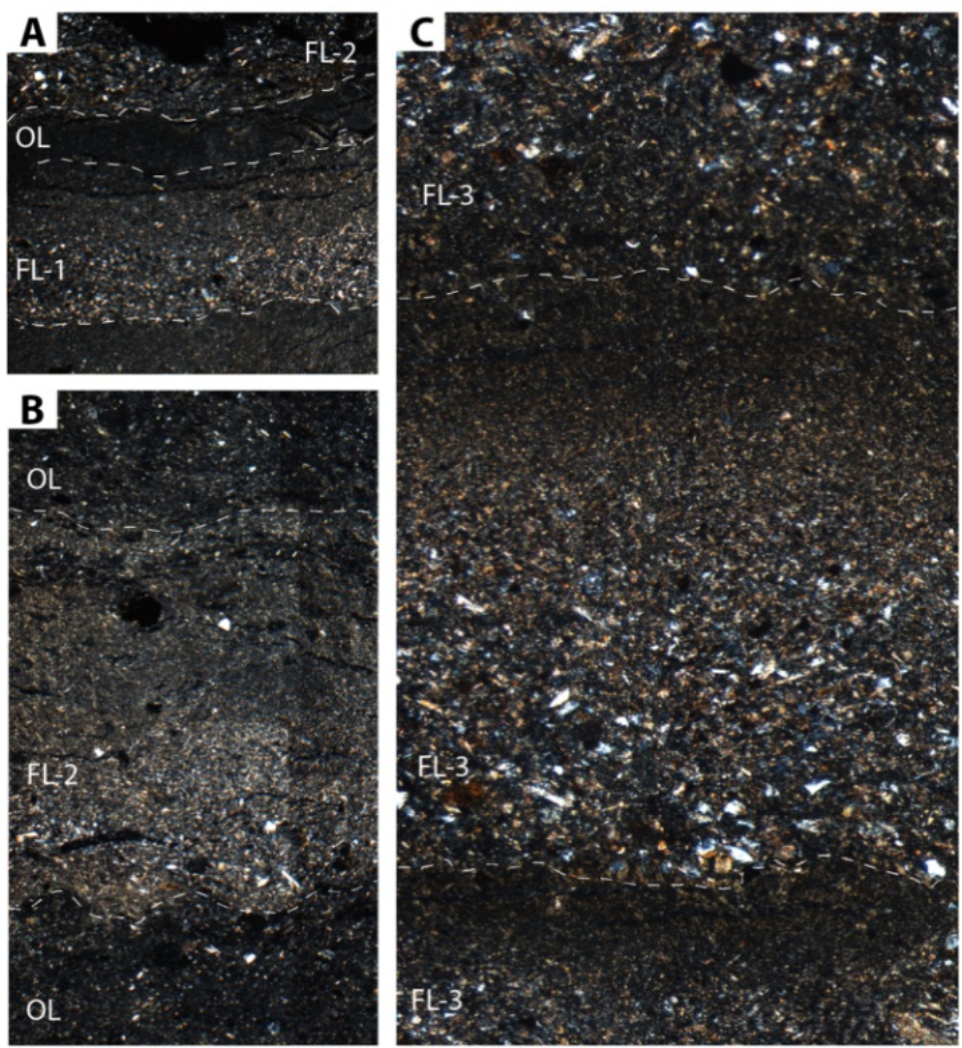

$200 \mu \mathrm{m}$ 


\section{Appendix DR5: Simplified pollen diagram of core ALO11}

Percentages are calculated according to the total pollen sum. Anthropic pollen is the sum of the counts of Plantago, Rumex, Urtica, Mentha and Chenopodiaceae. Exaggeration percentages are by a factor of 5 .

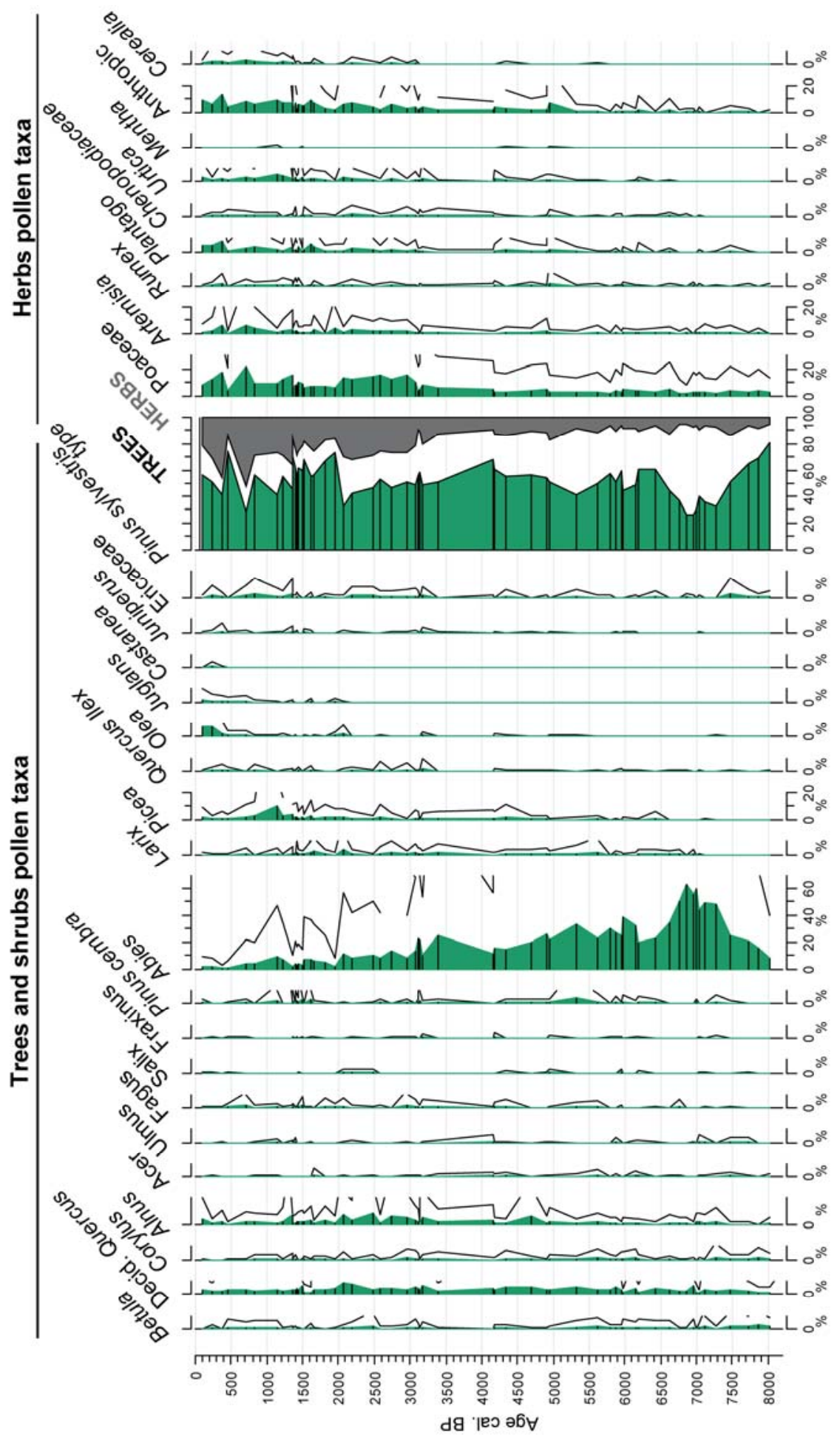




\section{Appendix DR6: Age-depth model of core ALO11 and dry bulk density}

Accepted ${ }^{14} \mathrm{C}$ ages are represented in blue by their probability density function. ${ }^{210} \mathrm{~Pb}$ data constrained by ${ }^{137} \mathrm{Cs}$ peaks are represented in light blue. The rejected age (red cross) consists of terrestrial macroremains. Considering that all the other ages before and after are concordant stratigraphically, this specific sample is probably too old. This may be due to long-term catchment sequestering of these macroremains. The best model fit is given by the thick black line, and the $95 \%$ confidence interval given by the thin lines. The model has been run on the sediment depth after removing thicknesses of all flood layers (minimum of $200 \mu \mathrm{m}$ ) corresponding to instantaneous deposition. Note that no relationship is observed between the dry bulk density and the sediment depth.

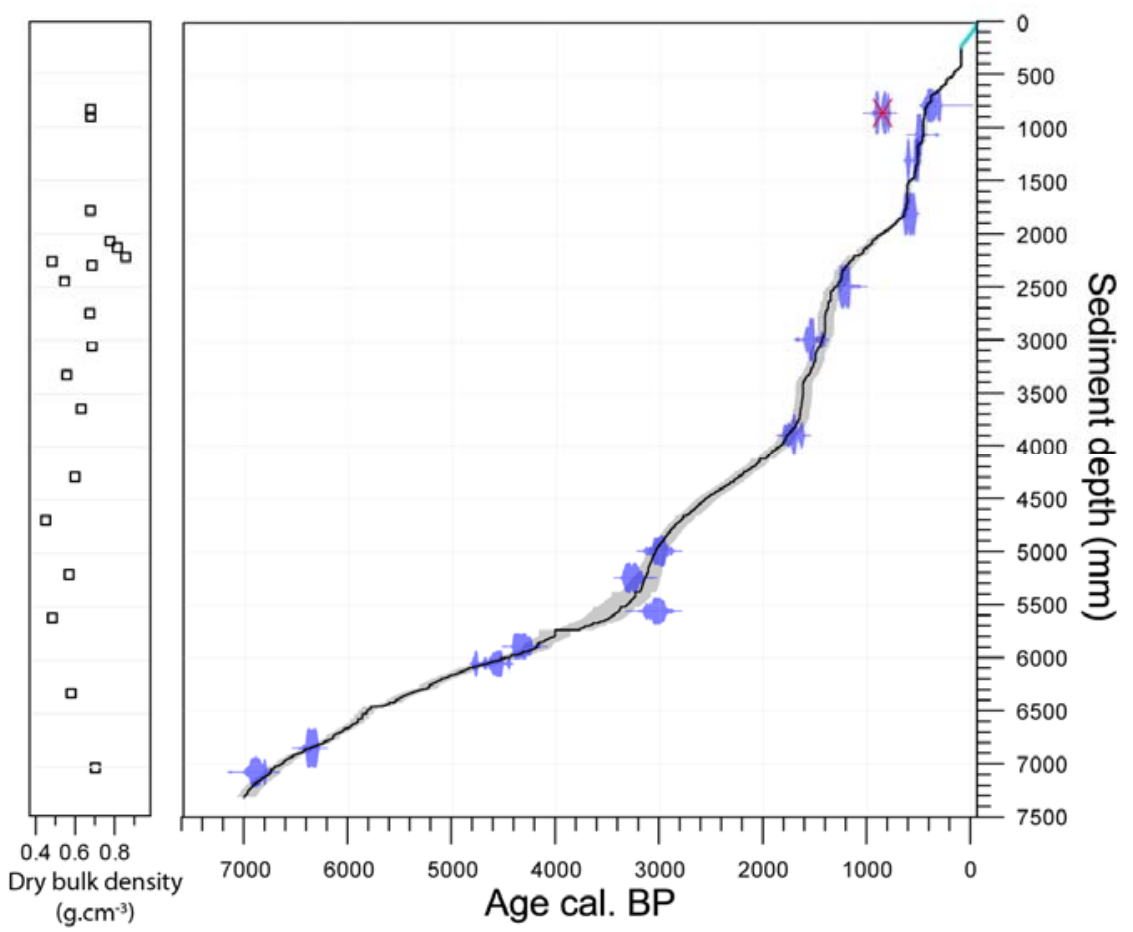




\section{Appendix DR7: Chronological controls of core ALO11}

Samples excluded for age-depth modelling are in italics: (1) Brisset et al., 2014; (2) Etienne et al., 2013; (3) Wilhelm et al., 2015.

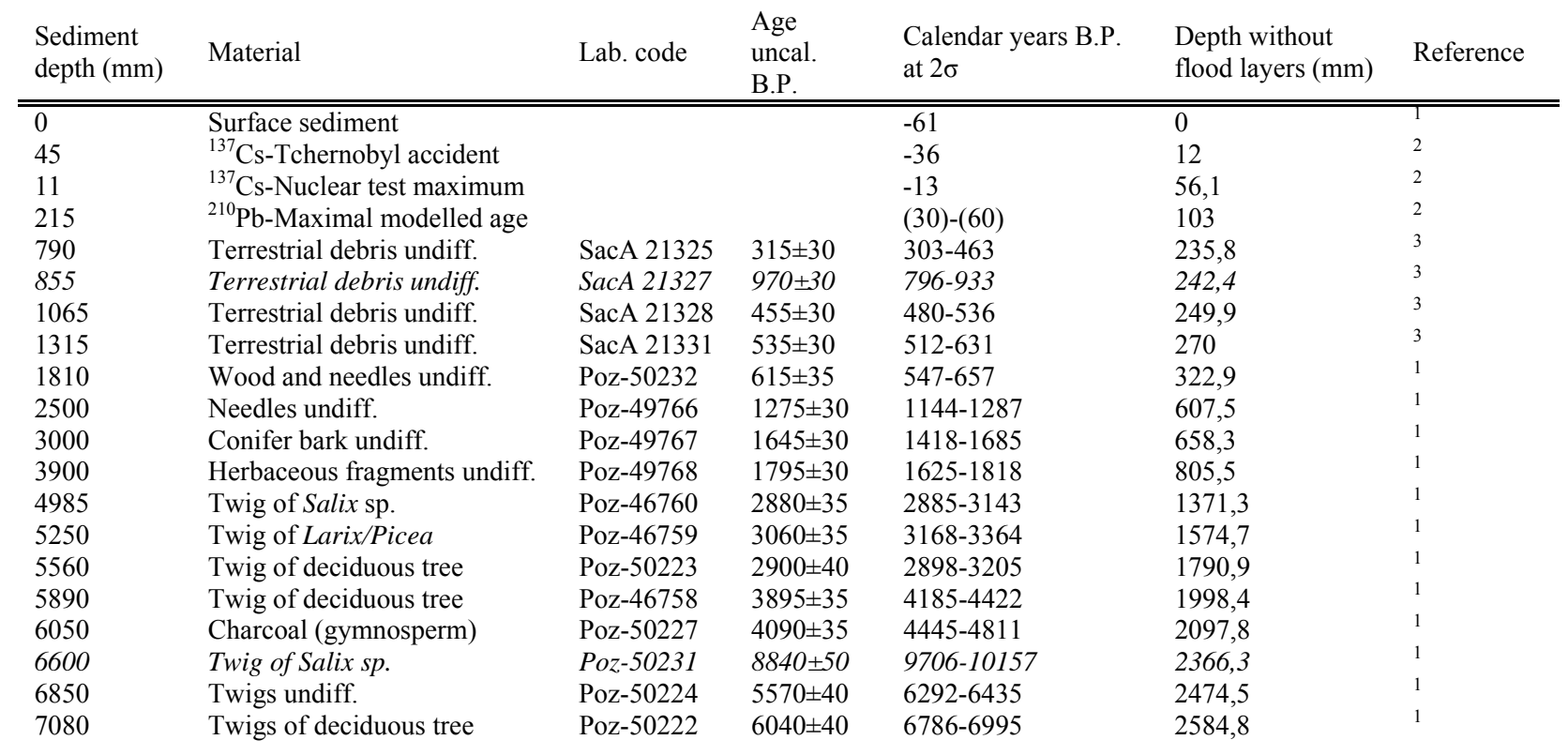

Brisset, E. et al., 2014, A new contribution to the chronology of the deglaciation in the Upper Verdon Valley (Lake Allos, Southern French Alps): Quaternaire, v. 25(2), p. 147-156.

Etienne, D., et al., 2013, Influence of sample location and livestock numbers on Sporormiella concentrations and accumulation rates in surface sediments of Lake Allos, French Alps: J. Paleolimnol., v. 49, p. 117-127.

Wilhelm, B., et al., 2015, Is a regional flood signal reproducible from lake sediments? Sedimentology, v. 62 , p. $1103-1117$. 
Appendix DR8: Results of Mann-Whitney tests evaluating changes in Flood Layer (FL) thickness as a function of different types of vegetation cover and levels of human impact.

The test evaluates whether the null hypothesis 'FL thicknesses from two periods of different vegetation cover have identical distributions with equal medians' can be rejected at a significance level of 0.01 , against the alternative that they do not have equal medians (according to the given p-value). The three classes defined are (A) Fine silts from 0 to $20 \mu \mathrm{m}$ (FL-1). (B) Medium silts from 20 to $50 \mu \mathrm{m}$ (FL-2). (C) Fine sands from 50 to $100 \mu \mathrm{m}$ (FL-3).

\begin{tabular}{|c|l|l|l|l|}
\cline { 2 - 5 } \multicolumn{2}{|c|}{} & \multicolumn{3}{c|}{ Null hypothesis } \\
\cline { 2 - 5 } \multicolumn{2}{|c|}{} & $\begin{array}{l}\text { FL thickness during } \\
\text { period of 'open forest' is } \\
\text { equal to that of 'dense } \\
\text { forest' }\end{array}$ & $\begin{array}{l}\text { FL thickness during } \\
\text { period of 'increasing } \\
\text { human impact' is equal to } \\
\text { that of 'open forest' }\end{array}$ & $\begin{array}{l}\text { FL thickness during period } \\
\text { of 'strong human impact' is } \\
\text { equal to that of 'increasing } \\
\text { human impact' }\end{array}$ \\
\hline $\begin{array}{c}\text { Flood layer } \\
\text { grain-size } \\
\text { class }\end{array}$ & FL-1 & Cannot be rejected & 0.0041 & 0.0002 \\
\cline { 2 - 5 } & FL-2 & Cannot be rejected & Cannot be rejected & 0.0000 \\
\cline { 2 - 5 } & FL-3 & Cannot be rejected & Cannot be rejected & 0.0000 \\
\hline
\end{tabular}


Appendix DR9: Postcards and photographs showing "natural” reforestation of the landscape surrounding Lake Allos in the late nineteenth century and in 2011 AD.

(A) From the northern shores of the lake looking toward the south. (B) From the southern shores looking toward the north.

Late 19th century

2011 AD
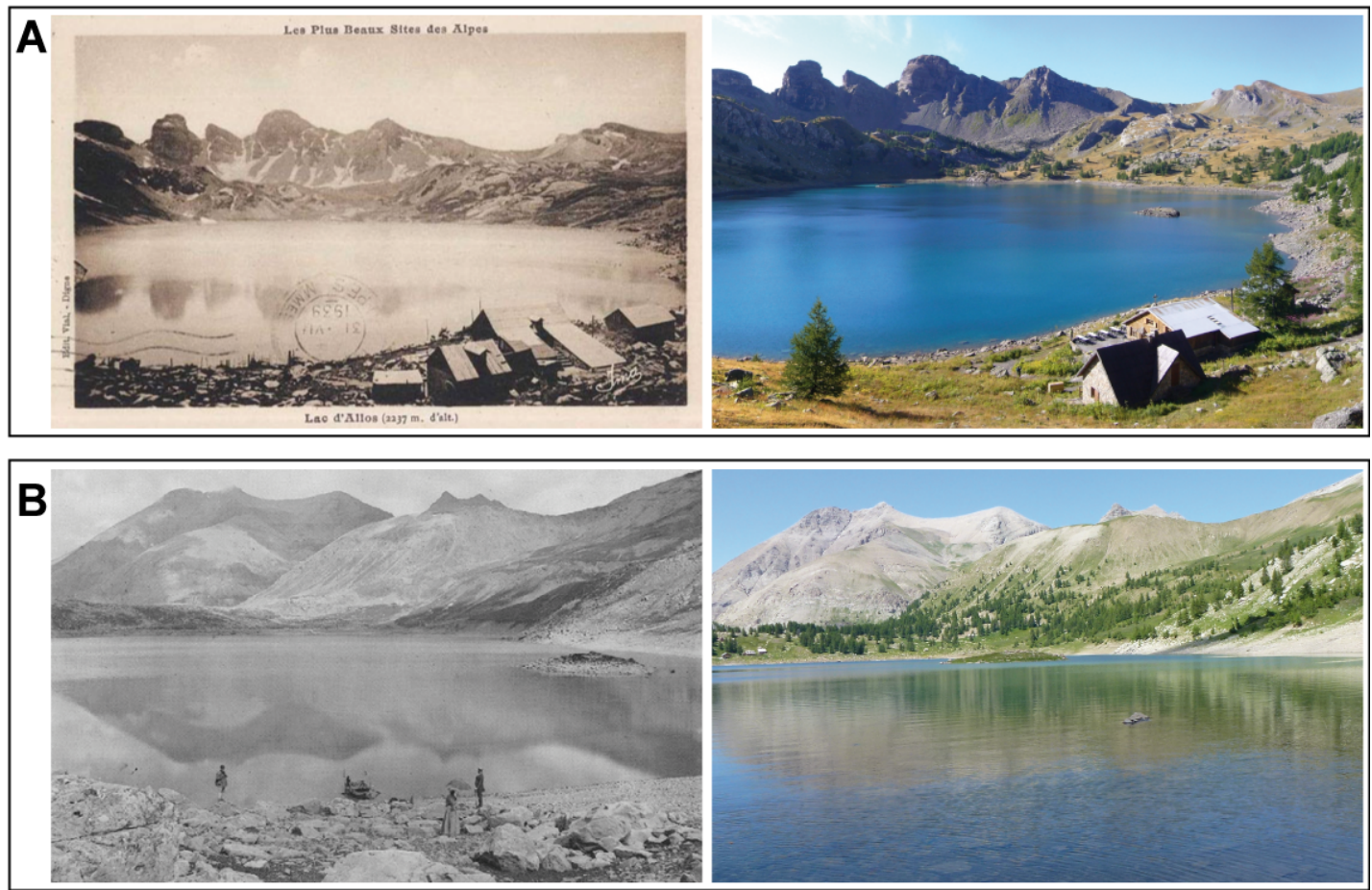